\title{
Identifying preferred management option of recreational fishing by combining an integrated agent-based simulation model and the AHP-TOPSIS evaluation method
}

\author{
$\underline{\text { L. Gao }}^{\text {a }}$ and Atakelty Hailu ${ }^{\text {b }}$ \\ ${ }^{a}$ CSIRO Land and Water, PMB 2, Glen Osmond, Adelaide, South Australia 5064, Australia \\ ${ }^{b}$ School of Agricultural and Resource Economics, University of Western Australia, 35 Stirling Highway, \\ Perth, Western Australia 6009, Australia \\ Email addresses: $\underline{\text { r.leigao@gmail.com and atakelty.hailu@uwa.edu.au }}$
}

\begin{abstract}
Most natural resource management issues are controversial. Typically social, economic, and a variety of environmental objectives need to be considered when identifying a preferred option from among alternative management strategies. The identification of best options is also technically challenging because of the lack of scientific tools to inform resource managers of future responses/impacts of alternative management actions, and to deal with many and possibly conflicting objectives.
\end{abstract}

The management of recreational fishing is such a typical example, where so far most management strategies tend to be ad hoc, and are seldom supported by scientific modelling and evaluation. Arbitrary management decisions lead to inefficient utilization of resource stocks. Research and evaluation tools that can assist resource managers assess the full range of potential impacts of management changes and select the best options against complex criteria are needed to improve decision making.

This paper proposes a decision support system which aims at greatly improving stakeholder dialogue and decision making for recreational fishing management. The system consists of two main components: an integrated agent-based model for simulating recreational fishing behavior and reef ecosystem dynamics; and an evaluation model based on the analytic hierarchy process (AHP) together with a technique for order performance by similarity to ideal solution (TOPSIS). The latter is responsible for assessing alternative strategies based on the simulation outputs generated by the former.

The agent-based simulation (ABS) model can be applied to other environments, but in this particular case it focuses on recreational fishing behaviour within a coral reef ecosystem. Recreational fishing behaviour specifications are based on empirical models estimated using survey data. The marine reef environment is modelled as a system with different trophic levels identifying algal and coral growth as well as two types of fish (piscivores and herbivores). The integrated model is able to keep track of not only biophysical feedback effects, but also complex socio-economic benefits or non-market values that are reflected in market transactions. In the outcome evaluation component of the system, the AHP is used to structure and rate all related criteria, and the fuzzy-TOPSIS method is used to obtain final rankings in terms of simulated socioeconomic and biophysical outcomes.

Preliminary results using the proposed system to assess a set of management strategies for recreational fishing in the Ningaloo Marine Park, an iconic coral reef system in Western Australia, illustrate the usefulness of the solution.

Keywords: multiple criteria decision making, decision support system, integrated economic-biophysical modelling, agent-based model, AHP, TOPSIS 


\section{INTRODUCTION}

Many natural resources are threatened by human activities. How human impact should be managed is still a subject of debate in many cases. Typically, identifying a preferred option from a multitude of alternative strategies requires resource managers to weigh carefully trade-offs among a variety of social, economic, and environmental outcomes. This process becomes even more challenging when managers do not have access to scientific tools that they could use to assess the impacts of alternative actions.

One case where the decision making difficulties are still great is recreational fishing. So far most management strategies tend to be ad hoc and are seldom supported by scientific modelling and evaluation. Arbitrary management decisions lead to inefficient utilization of fish stocks. Evaluation tools that can assist resource managers assess the full range of potential impacts of management changes, and select the best options against complex decision criteria, are needed to improve decision making.

The optimal selection of recreational fishing strategies is a problem in multiple criteria decision-making (MCDM) (Ho et al., 2010). Some decision support systems (DSS) have been developed to facilitate the projection of potential future outcomes under alternative fisheries management scenarios. However, these DSS do not assess the economic value of recreational fishing or incorporate our understanding of the drivers of recreational fishing choices made by anglers. What is more, these DSS fail to deal with the multiple criteria decision making nature of the management problem.

This paper aims to address the gaps through the development of a decision support system (DSS) using an integrated agent-based simulation (ABS) model and an AHP-TOPSIS outcome evaluation method. Such a DSS is a functionally integrated computer system that allows resource managers to incorporate multiple objectives and the concerns of stakeholders into decision-making, examine the expected effects of different management strategies, and thus improve stakeholder dialogue in recreational fishing management.

The system consists of two main components: an integrated ABS model for mimicking recreational fishing and reef ecosystem dynamics; and a strategy identification model based on the analytic hierarchy process (AHP) together with a technique for order performance by similarity to ideal solution (TOPSIS). The latter is responsible for assessing alternative strategies based on the simulation outputs generated by the former.

Angler behaviour and biophysical simulation is undertaken in the ABS model. The ABS is a bottom-up approach that abstracts a complex system as a collection of autonomous agents. The agent-based or individual-based approach provides a number of significant advantages over traditional methods (Bonabeau, 2002, Gao et al., 2006). Spatial aspects as well as the dynamics in fishing behavior are easier to model. It is possible to undertake "what-if" scenario analyses covering a range of economic and biophysical outcomes. The integrated ABS model is implemented as the simulation part of the proposed DSS. The strategy identification part of the DSS starts with the specification of preferences over outcomes, and then combines these preferences together with simulated bio-economic outcomes from the ABS to rank alternative management strategies in a consistent manner. We choose AHP to determine the importance weights of evaluation criteria, and fuzzy TOPSIS to obtain the performance ratings of the feasible alternatives in linguistic values parameterized with triangular fuzzy numbers.

In the next section, we describe the system architecture of the proposed DSS. Then we present the integrated ABS model and the AHP-TOPSIS evaluation approach. In Section 3, we present an application of the DSS in which fishing management strategies are evaluated. The paper is summarized in Section 4.

\section{A DSS FOR MANAGEMENT OPTION IDENTIFICATION OF RECREATIONAL FISHING}

The DSS developed here addresses two key gaps mentioned above: (1) the absence of empirically-based tools for predicting outcomes from management decisions, and (2) the complexities associated with ranking multiple management strategies that are under consideration. Below, we describe the system starting with an overview of the overall architecture followed by descriptions of its components.

\subsection{System architecture}

The system architecture is demonstrated in Figure 1. The integrated ABS model for recreational fishing which is depicted on the left hand side in the figure is responsible for generating management outcome indicators. These outcomes are further used as inputs into the strategy identification model which is depicted on the right hand side. Then in the strategy identification model, a four-step procedure is used to provide the best management advice. 


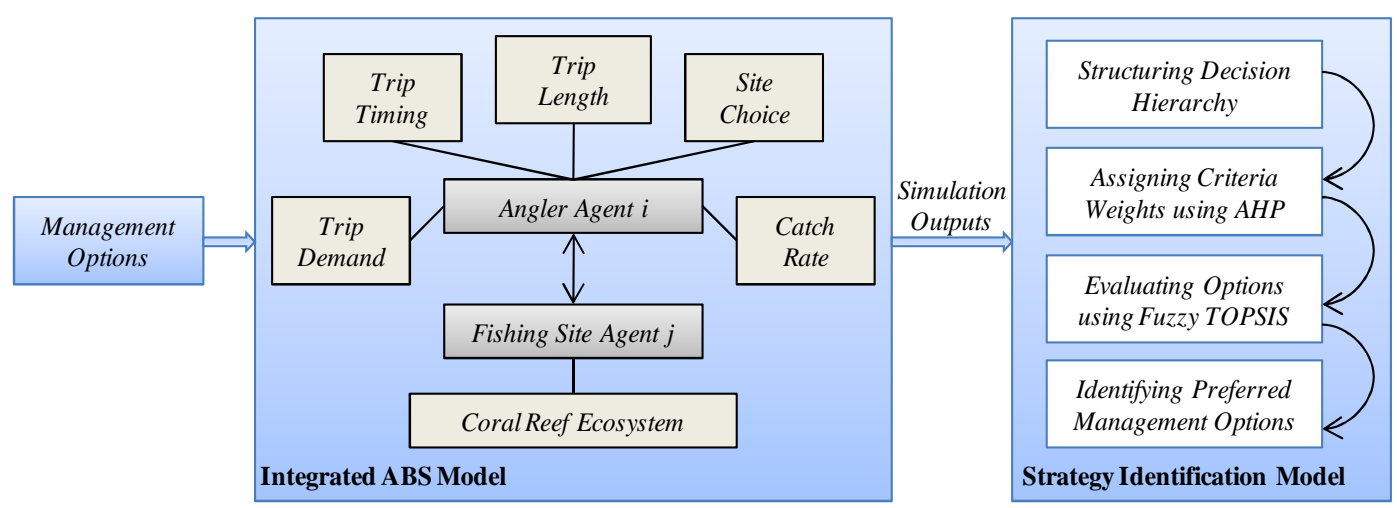

Figure 1. The architecture of the decision support system.

\subsection{The integrated $\mathrm{ABS}$ model}

Our ABS model is the first model to combine econometrically estimated models of agent behaviours with a biophysical model of coral reefs. Recreational anglers and angling sites are all modelled as agents. As shown in Figure 1, the model includes six sub-models, where five are econometric models and include the following: trip demand model, trip timing model, trip length model, site choice model, and catch rate model. The trip timing and trip length models are based on Hailu and Gao (2012). The other econometric models are based on a previous study (Raguragavan et al., 2010). These models predict, respectively, the number of fishing trips an angler takes in a year, the timing of a trip in a year, the length or duration of a trip, the choice of recreational site in a trip, and the angler's expected catch. The sixth sub-model is a coral reef ecosystem model (Gao and Hailu, 2011) that describes interactions among four components in a coral reef environment, namely, algae, corals as well as herbivore and piscivore fish.

This model has been used as a stand-alone model to evaluate particular management strategies (Gao and Hailu, 2011) without the multi-criteria evaluation component presented in this DSS. For more details about the ABS model, we refer readers to Gao and Hailu (2011).

\subsection{The strategy selection model}

The AHP-TOPSIS method, which is described by Dağdeviren et al. (2009), is adopted. The proposed model for identifying preferred strategy consists of these four basic steps: (1) determining a set of decision criteria and structuring a decision hierarchy over these criteria; (2) calculating a consistent set of preference weights for outcomes in the criteria set using the AHP; (3) evaluating alternative management options using the fuzzy TOPSIS approach; and (4) identifying preferred management strategies from those under consideration.

\section{The AHP method}

As one of the most popular multi-criteria decision making (MCDM) methods, the AHP has many advantages (Saaty and Vargas, 2000), such as providing a measure of consistency in decision makers' judgments as well as pair-wise comparisons that are simple enough to work with and often are preferred by the decision makers. The basic steps involved in this method are as follows.

(a) Structure the decision problem: This involves identifying the alternative choices and the hierarchy of outcomes, with outcomes possibly defined to include an overall goal followed by outcome criteria (sub-criteria).

(b) Articulate preferences over criteria: This process involves describing preferences over outcomes in the form of weights on a pair-wise comparison basis. The weight specification exercise is simplified by first using the pair-wise comparison which is easier to work with. Second, a fundamental scale of values, similar to those shown in Table 1, can be used to simplify the representation of the intensities of preferences.

(c) Construct an evaluation matrix: This process involves defining, using the pair-wise values, an $n$-criteria

Table 1. The fundamental scale of pair-wise comparisons usually used by the AHP.

\begin{tabular}{ll}
\hline Definition & $a_{i j}$ \\
\hline Equally important between $i$ and $j$ & 1 \\
$i$ is moderately more important than $j$ & 3 \\
$i$ is strongly more important than $j$ & 5 \\
$i$ is very strongly more important than $j$ & 7 \\
$i$ is extremely more important than $j$ & 9 \\
Intermediate values & $2,4,6,8$ \\
For inverse comparison & Reciprocals \\
\hline
\end{tabular}


evaluation matrix $\mathrm{A}$ in which every element $a_{i j}(i, j=1,2, \ldots, n)$ is the quotient/ratio of preference values attached to the criteria, as shown in equation (1).

$$
A=\left[\begin{array}{cccc}
a_{11} & a_{12} & \cdots & a_{1 n} \\
a_{21} & a_{22} & \cdots & a_{2 n} \\
\vdots & \vdots & \ddots & \vdots \\
a_{n 1} & a_{n 2} & \cdots & a_{n n}
\end{array}\right], a_{i i}=1, a_{j i}=1 / a_{i j}, a_{i j} \neq 0
$$

(d) Derive criteria weights: The aim in this step is to transform the preferences stated above into a set of weights that could be attached to the multiple outcomes. To impose a consistency requirement, this procedure calculates the maximum eigenvalue $\lambda_{\max }$ and a corresponding eigenvector $w$ for the matrix $A$. Then, this maximum eigenvalue is used to develop a consistency measure, using a procedure that accounts for the effects of the size of the criteria set $n$ as shown below. This measure, known as the consistency ratio or $C R$, is used to determine whether the preference judgments embodied in $A$ are consistent. If they are not, the preference represented in the matrix $A$ are adjusted and the procedure repeated until $C R$ lies in the desired range. Details on this procedure are provided in (Saaty and Vargas, 2000).

\section{The fuzzy TOPSIS method}

The TOPSIS method defines that the best alternative would be the one that is nearest to the positive-ideal solution and farthest from the negative-ideal solution. The positive-ideal solution is composed of all best attainable criteria values, whereas the negative-ideal solution consists of all worst possible criteria values. However, the standard method is often criticized for its inability to adequately handle the inherent uncertainty and imprecision associated with the mapping of decision-makers' perceptions to crisp values. Thus, the fuzzy TOPSIS method was developed to address this shortcoming. Triangular fuzzy numbers are used for the fuzzy TOPSIS method, which includes the following main steps (Dağdeviren et al., 2009):

Step 1: Choose the linguistic ratings $\left(\tilde{x}_{i j}=\left(x_{i j 1}, x_{i j 2}, x_{i j 3}\right)\right.$, where $x_{i j 1}, x_{i j 2}, x_{i j 3}$ are three elements of this triangular fuzzy number, $i$ represents the index of an attribute or criterion, $i=1,2, \ldots, n$, and $j$ denotes the index of a management alternative, $j=1,2, \ldots, J$ ) for alternatives with respect to criteria. The fuzzy linguistic rating $\left(\tilde{x}_{i j}\right)$ preserves the property that the ranges of normalized triangular fuzzy numbers belong to $[0,1]$; thus, there is no need for normalization.

Step 2: Considering the different weight of each criterion, the weighted normalized fuzzy decision matrix is calculated as

$$
\tilde{V}=\left[\tilde{v}_{i j}\right]_{n \times J}, i=1,2, \ldots, n, j=1,2, \ldots, J
$$

where the weighted normalized value $\tilde{v}_{i j}=\tilde{x}_{i j}(\cdot) w_{i}$.

Step 3: Identify positive-ideal $\left(A^{*}\right)$ and negative-ideal $\left(A^{-}\right)$solutions. The fuzzy positive-ideal solution $\left(\right.$ FPIS,$A^{*}$ ) and the fuzzy negative-ideal solution (FNIS, $A^{-}$) are shown in the following equations:

$$
\begin{aligned}
A^{*} & =\left\{\tilde{v}_{1}^{*}, \ldots, \tilde{v}_{i}^{*}, \ldots, \tilde{v}_{n}^{*}\right\} \\
A^{-} & =\left\{\tilde{v}_{1}^{-}, \ldots, \tilde{v}_{i}^{-}, \ldots, \tilde{v}_{n}^{-}\right\}
\end{aligned}
$$

where $\tilde{v}_{i}^{*}=\left\{\left(\max _{j} \tilde{v}_{i j} \mid i \in I^{\prime}\right),\left(\min _{j} \tilde{v}_{i j} \mid i \in I^{\prime \prime}\right)\right\} ; \tilde{v}_{i}^{-}=\left\{\left(\min _{j} \tilde{v}_{i j} \mid i \in I^{\prime}\right),\left(\max _{j} \tilde{v}_{i j} \mid i \in I^{\prime \prime}\right)\right\} ; i=$ $1,2, \ldots, n ; j=1,2, \ldots, J ; I^{\prime}$ is associated with benefit criteria (the larger the better); and $I^{\prime \prime}$ is associated with cost criteria (the smaller the better).

Step 4: Calculate the distance of each alternative from $\mathrm{A}^{*}$ and $\mathrm{A}^{-}$using the following equations:

$$
\begin{aligned}
D_{j}^{*} & =\sum_{j=1}^{n} d\left(\tilde{v}_{i j}, \tilde{v}_{i}^{*}\right) j=1,2, \ldots, J \\
D_{j}^{-} & =\sum_{j=1}^{n} d\left(\tilde{v}_{i j}, \tilde{v}_{i}^{-}\right) j=1,2, \ldots, J
\end{aligned}
$$

Let $\tilde{a}=\left(a_{1}, a_{2}, a_{3}\right)$ and $\tilde{b}=\left(b_{1}, b_{2}, b_{3}\right)$ be two triangular fuzzy numbers, then the vertex method is defined to calculate the distance between them as $d(\tilde{a}, \tilde{b})=\sqrt{1 / 3\left[\left(a_{1}-b_{1}\right)^{2}+\left(a_{2}-b_{2}\right)^{2}+\left(a_{3}-b_{3}\right)^{2}\right]}$.

Step 5: Calculate similarities to ideal solution:

$$
C C_{j}=D_{j}^{-} /\left(D_{j}^{*}+D_{j}^{-}\right) \quad j=1,2, \ldots, J
$$

Step 6: Rank preference order. Choose an alternative with maximum $C C_{j}$ or rank alternatives according to $C C_{j}$ in descending order. 


\section{AN APPLICATION OF THE PROPOSED DSS}

We applied the proposed DSS to identify preferred management option of recreational fishing in the Ningaloo coral reef marine park of Western Australia. The data used in this paper are generated from our previous experiments of area closure (Gao and Hailu, 2011).

\subsection{Decision hierarchy}

Decision hierarchy structured with criteria and alternative management options is shown in Figure 2. There are three

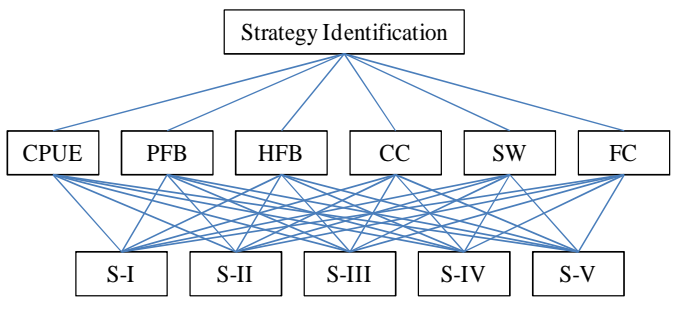

Figure 2. The decision hierarchy of strategy identification.

layers in the decision hierarchy. The first layer describes the overall goal which is determined as identifying a preferred strategy option. The criteria and alternative options are in the second and third layers, respectively.

A set of criteria to be considered for identifying a preferred management option are given in Table 2. These criteria could vary depending on what stakeholders consider important. The purpose here is to show how the DSS helps transform outcomes and preferences into decision.

Five site closure options are assessed. Strategy I is a "business-as-usual" strategy where there is no fishing area closure. Strategy II and III involve closing fishing site for 2 and 6 months, respectively, during the peak fishing period in the year. Strategy IV and $\mathrm{V}$ involve 2 and 6 month site closures, respectively, but during the low demand or trough fishing period in the year.

Table 2. Evaluation criteria and their explanation.

\begin{tabular}{ll}
\hline Criteria & Explanations \\
\hline Catch per unit effort (CPUE) & Measured by an average catches per trip \\
Piscivorous fish biomass (PFB) & High-value fish species which are main targets by anglers \\
Herbivorous fish biomass (HFB) & Low-value fish species \\
Coral cover (CC) & A major attraction for non-fishing recreationists \\
Social welfare (SW) & Economic surplus derived from fishing (Gao and Hailu, 2011) \\
Fees collected (FC) & The revenue of access fees collected \\
\hline
\end{tabular}

\subsection{Determining the weights of criteria using the AHP method}

After obtaining the decision hierarchy shown in Figure 2, the criteria weights for strategy identification are calculated using the AHP method. At this stage, the decision maker is given the task of forming individual pair-wise comparison matrices using the scales given in Table 1. Suppose the comparison matrix looks like the one showing in the first seven columns of Table 3. The AHP weights would then be those shown in the last column of the table. These weights are consistent, as the consistency ratio for this example is 0.0045 , which is less than the acceptance cut-off value of 0.1 .

Table 3. The pairwise comparison matrix for criteria.

\begin{tabular}{llllllll}
\hline $\begin{array}{l}\text { Strategy } \\
\text { Identification }\end{array}$ & CPUE & PFB & HFB & CC & SW & FC & Weights \\
\hline CPUE & 1 & $1 / 5$ & $1 / 3$ & $1 / 2$ & $1 / 4$ & $1 / 2$ & 0.0567 \\
PFB & 5 & 1 & 2 & 3 & 2 & 4 & 0.3519 \\
HFB & 3 & $1 / 2$ & 1 & 2 & 1 & 2 & 0.1893 \\
CC & 2 & $1 / 3$ & $1 / 2$ & 1 & $1 / 2$ & 1 & 0.1042 \\
SW & 4 & $1 / 2$ & 1 & 2 & 1 & 2 & 0.1987 \\
FC & 2 & $1 / 4$ & $1 / 2$ & 1 & $1 / 2$ & 1 & 0.0993 \\
CR $=0.0045$ & & & & & & & \\
\hline
\end{tabular}

\subsection{Evaluating alternative management options}

In this section, a ranking of alternative management options is determined using fuzzy TOPSIS. Linguistic values are used for identifying alternative management options. The membership functions of these linguistic values are shown in Figure 3, and the triangular fuzzy numbers related with these variables are shown in Table 4.

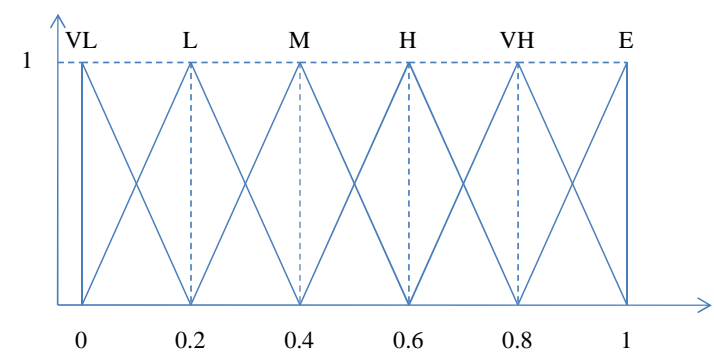

Figure 3. The membership function of linguistic values.
Table 4. Linguistic values and fuzzy numbers.

\begin{tabular}{ll}
\hline Linguistic values & Fuzzy numbers \\
\hline Very low (VL) & $(0,0,0.2)$ \\
Low (L) & $(0,0.2,0.4)$ \\
Medium (M) & $(0.2,0.4,0.6)$ \\
High (H) & $(0.4,0.6,0.8)$ \\
Very High (VH) & $(0.6,0.8,1)$ \\
Excellent (E) & $(0.8,1,1)$ \\
\hline
\end{tabular}


Modelling using triangular fuzzy numbers has proven to be an effective way for formulating decision problems where the information available is subjective and imprecise (Dağdeviren et al., 2009). The simulation results for the criteria are shown in Table 5. To convert the simulation values to linguistic values, we adopt a simple approach. Suppose the maximum simulation value of criterion $c$ is $v_{c}^{\max }$ and minimum value is $v_{c}^{\min }$. We can now divide the range $\left[v_{c}^{\min }, v_{c}^{\max }\right]$ into $m$ ( $m$ is the number of linguistic values and equals 6 in the case study) equal parts. As shown in Figure 4, which linguistic value a simulation value maps to depends on which part the simulation value falls into. For example, if a simulation value falls between $\left(v_{c}^{\max }-v_{c}^{\min }\right) / m$ and $2\left(v_{c}^{\max }-v_{c}^{\min }\right) / m$, its corresponding linguistic value should be "Low (L)".

Table 5. The simulation results for the criteria under low fishing pressure.

\begin{tabular}{|c|c|c|c|c|c|}
\hline \multirow[t]{2}{*}{ Criterion } & \multicolumn{4}{|c|}{ Strategy } & \multirow[b]{2}{*}{$\mathrm{V}$} \\
\hline & $\mathrm{I}$ & II & III & IV & \\
\hline CPUE (kg/trip) & 12.59 & 10.44 & 8.77 & 11.48 & 9.11 \\
\hline $\begin{array}{l}\text { Average piscivorous } \\
\text { fish biomass }\left(\mathrm{kg} / \mathrm{km}^{2}\right)\end{array}$ & 4057.10 & 3539.00 & 3338.62 & 3875.05 & 3374.62 \\
\hline $\begin{array}{l}\text { Average herbivorous } \\
\text { fish biomass }\left(\mathrm{kg} / \mathrm{km}^{2}\right)\end{array}$ & 1633.57 & 1599.38 & 1580.62 & 1612.76 & 1592.24 \\
\hline Coral cover $(\%)$ & 24.62 & 31.76 & 34.19 & 27.52 & 34.19 \\
\hline Social welfare (\$) & 527455.81 & 516089.29 & 487597.95 & 523168.57 & 498966.67 \\
\hline Fee Collected & 46153.57 & 46076.43 & 46068.57 & 46155.71 & 46077.14 \\
\hline
\end{tabular}

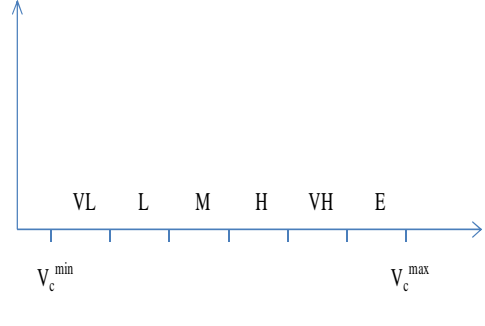

Figure 4. The determination of linguistic values.

Thus, the simulation values are converted to linguistic values, as shown in Table 6. As these linguistic values are not mathematically operable, these linguistic values are further transformed into fuzzy numbers using Table 4. This is the first step of the fuzzy TOPSIS procedure. The second step of the procedure is to obtain a fuzzy weighted decision table, which is given in Table 7 . It is seen that the elements $\tilde{v}_{i j}(\forall i, j)$ are normalized positive triangular fuzzy numbers and their ranges belong to the closed interval $[0,1]$. So the fuzzy positiveideal solution (FPIS, $A^{*}$ ) and the fuzzy negative-ideal solution (FNIS, $A^{-}$) are defined as $\tilde{v}_{i}^{*}=(1,1,1)$ and $\tilde{v}_{i}^{-}=(0,0,0)$ for a benefit criterion (the larger the better), and $\tilde{v}_{i}^{*}=(0,0,0)$ and $\tilde{v}_{i}^{-}=(1,1,1)$ for a cost criterion (the smaller the better). Note that there are only benefit criteria in this case study. In order to show steps 3-5, the process of calculating $\mathrm{CC}_{\mathrm{S}-\mathrm{I}}$ is used as an example, which is shown in Figure 5.

Table 6. Fuzzy evaluation matrix for strategy identification.

\begin{tabular}{lllllll}
\hline & CPUE & PFB & HFB & CC & SW & FC \\
\hline S-I & E & E & E & VL & E & E \\
S-II & M & L & M & H & H & VL \\
S-III & VL & VL & VL & E & VL & VL \\
S-IV & H & H & H & L & E & E \\
S-V & VL & VL & L & E & L & VL \\
S-I & $(0.8,1,1)$ & $(0.8,1,1)$ & $(0.8,1,1)$ & $(0,0,0.2)$ & $(0.8,1,1)$ & $(0.8,1,1)$ \\
S-II & $(0.2,0.4,0.6)$ & $(0,0.2,0.4)$ & $(0.2,0.4,0.6)$ & $(0.4,0.6,0.8)$ & $(0.4,0.6,0.8)$ & $(0,0,0.2)$ \\
S-III & $(0,0,0.2)$ & $(0,0,0.2)$ & $(0,0,0.2)$ & $(0.8,1,1)$ & $(0,0,0.2)$ & $(0,0,0.2)$ \\
S-IV & $(0.4,0.6,0.8)$ & $(0.4,0.6,0.8)$ & $(0.4,0.6,0.8)$ & $(0,0.2,0.4)$ & $(0.8,1,1)$ & $(0.8,1,1)$ \\
S-V & $(0,0,0.2)$ & $(0,0,0.2)$ & $(0,0.2,0.4)$ & $(0.8,1,1)$ & $(0,0.2,0.4)$ & $(0,0,0.2)$ \\
& & & & & & 0.1987 \\
Weights & 0.0567 & 0.3519 & 0.1893 & 0.1042 & & 0.0993 \\
\hline
\end{tabular}

Table 7. Weighted evaluation for the alternative strategies.

\begin{tabular}{|c|c|c|c|c|c|c|}
\hline & CPUE & PFB & HFB & $\mathrm{CC}$ & SW & $\mathrm{FC}$ \\
\hline S-I & $\begin{array}{l}(0.045,0.057, \\
0.057)\end{array}$ & $\begin{array}{l}(0.282,0.352, \\
0.352)\end{array}$ & $\begin{array}{l}(0.151,0.189, \\
0.189)\end{array}$ & $(0,0,0.021)$ & $\begin{array}{l}(0.159,0.199, \\
0.199)\end{array}$ & $\begin{array}{l}(0.079,0.099, \\
0.099)\end{array}$ \\
\hline S-II & $\begin{array}{l}(0.011,0.023, \\
0.034)\end{array}$ & $(0,0.070,0.141)$ & $\begin{array}{l}(0.038,0.076, \\
0.114)\end{array}$ & $\begin{array}{l}(0.042,0.063, \\
0.083)\end{array}$ & $\begin{array}{l}(0.079,0.119, \\
0.159)\end{array}$ & $(0,0,0.020)$ \\
\hline S-III & $(0,0,0.011)$ & $(0,0,0.070)$ & $(0,0,0.038)$ & $\begin{array}{l}(0.083,0.104, \\
0.104)\end{array}$ & $(0,0,0.040)$ & $(0,0,0.020)$ \\
\hline S-IV & $\begin{array}{l}(0.023,0.034 \\
0.045)\end{array}$ & $\begin{array}{l}(0.141,0.211, \\
0.282)\end{array}$ & $\begin{array}{l}(0.076,0.114 \\
0.151)\end{array}$ & $(0,0.021,0.042)$ & $\begin{array}{l}(0.159,0.199 \\
0.199)\end{array}$ & $\begin{array}{l}(0.079,0.099, \\
0.099)\end{array}$ \\
\hline S-V & $(0,0,0.011)$ & $(0,0,0.070)$ & $(0,0.038,0.076)$ & $\begin{array}{l}(0.083,0.104 \\
0.104)\end{array}$ & $(0,0.040,0.079)$ & $(0,0,0.020)$ \\
\hline$A^{*}$ & $\tilde{v}_{C P U E}^{*}=(1,1,1)$ & $\tilde{v}_{P F B}^{*}=(1,1,1)$ & $\tilde{v}_{H F B}^{*}=(1,1,1)$ & $\tilde{v}_{C C}^{*}=(1,1,1)$ & $\tilde{v}_{S W}^{*}=(1,1,1)$ & $\tilde{v}_{F C}^{*}=(1,1,1)$ \\
\hline$A^{-}$ & $\tilde{v}_{C P U E}^{-}=(0,0,0)$ & $\tilde{v}_{P F B}^{-}=(0,0,0)$ & $\tilde{v}_{H F B}^{-}=(0,0,0)$ & $\tilde{v}_{C C}^{-}=(0,0,0)$ & $\tilde{v}_{S W}^{-}=(0,0,0)$ & $\tilde{v}_{F C}^{-}=(0,0,0)$ \\
\hline
\end{tabular}


Gao and Hailu, Identifying preferred management option of recreational fishing

$$
\begin{array}{rrr}
\mathrm{D}_{\mathrm{S}-\mathrm{I}}^{*}=\sqrt{1 / 3\left[(0.045-1)^{2}+(0.057-1)^{2}+(0.057-1)^{2}\right]} & \mathrm{D}_{\mathrm{S}-\mathrm{I}}^{-}=\sqrt{1 / 3\left[(0.045-0)^{2}+(0.057-0)^{2}+(0.057-0)^{2}\right]} \\
& +\sqrt{1 / 3\left[(0.282-1)^{2}+(0.352-1)^{2}+(0.352-1)^{2}\right]} & +\sqrt{1 / 3\left[(0.282-0)^{2}+(0.352-0)^{2}+(0.352-0)^{2}\right]} \\
& +\sqrt{1 / 3\left[(0.151-1)^{2}+(0.189-1)^{2}+(0.189-1)^{2}\right]} & +\sqrt{1 / 3\left[(0.151-0)^{2}+(0.189-0)^{2}+(0.189-0)^{2}\right]} \\
& +\sqrt{1 / 3\left[(0-1)^{2}+(0-1)^{2}+(0.021-1)^{2}\right]} & +\sqrt{1 / 3\left[(0-0)^{2}+(0-0)^{2}+(0.021-0)^{2}\right]} \\
& +\sqrt{1 / 3\left[(0.159-1)^{2}+(0.199-1)^{2}+(0.199-1)^{2}\right]} & +\sqrt{1 / 3\left[(0.159-0)^{2}+(0.199-0)^{2}+(0.199-0)^{2}\right]} \\
& +\sqrt{1 / 3\left[(0.079-1)^{2}+(0.099-1)^{2}+(0.099-1)^{2}\right]} & +\sqrt{1 / 3\left[(0.079-0)^{2}+(0.099-0)^{2}+(0.099-0)^{2}\right]} \\
=5.158 & =0.852 \\
& &
\end{array}
$$

Figure 5. An example of calculating $C C_{j}$.

Similar calculations are done for the other alternatives and the results of fuzzy TOPSIS analyses are summarized in Table 8 . Based on the $C C_{j}$ values, the ranking of the alternatives in a descending order are S-I, S-IV, S-II, S-V and S-III. The DSS indicates that S-I is the best management alternative, with a $C C$ value of 0.142 .
Table 8 . The fuzzy TOPSIS result.

\begin{tabular}{lccc}
\hline Strategy options & $D_{j}^{*}$ & $D_{j}^{-}$ & $C C_{j}$ \\
\hline S-I & 5.158 & 0.852 & 0.142 \\
S-II & 5.646 & 0.397 & 0.066 \\
S-III & 5.844 & 0.201 & 0.033 \\
S-IV & 5.345 & 0.678 & 0.113 \\
S-V & 5.793 & 0.256 & 0.042 \\
\hline
\end{tabular}

\section{CONCLUSIONS}

This paper has provided a DSS to aid decision making process for a complex situation involving multiple strategies each of which generates multiple social, economic and environmental outcomes. The DSS consists of an integrated agent-based model for simulating recreational fishing and reef ecosystem dynamics, and an AHP-TOPSIS evaluation approach for assessing alternative strategies based on simulation outputs. In our demonstration of the proposed DSS, five alternative management strategies are considered for the management of recreational fishing in the Ningaloo Marine Park of Western Australia. The results highlight the effectiveness of the proposed DSS as a consistent means for specifying stakeholder values or preferences and incorporating these in the assessment of strategy outcomes predicted by scientific models.

\section{ACKNOWLEDGEMENTS}

Research reported here was funded through the Ningaloo Collaboration Cluster, CSIRO Wealth from Oceans Flagship Program.

\section{REFERENCES}

Bonabeau, E. (2002). Agent-based modeling: Methods and techniques for simulating human systems. Proceedings of the National Academy of Science, 99(3), 7280-7287.

Dağdeviren, M., Yavuz, S. and Kılınç, N. (2009). Weapon selection using the AHP and TOPSIS methods under fuzzy environment. Expert Systems with Applications, 36(4), 8143-8151.

Gao, L., Ding, Y.-S. and Ying, H. (2006). An adaptive social network-inspired approach to resource discovery for the complex grid systems. International Journal of General Systems, 35(3), 347-360.

Gao, L. and Hailu, A. (2011). Evaluating the effects of area closure for recreational fishing in a coral reef ecosystem: The benefits of an integrated economic and biophysical modelling. Ecological Economics, $70(10), 1735-1745$.

Hailu, A. and Gao, L. (2012). Recreational trip timing and duration prediction. Tourism Economics, In press. Also available online at: AgEcon Search (http://ageconsearch.umn.edu/handle/97474).

Ho, W., Xu, X. W. and Dey, P. K. (2010). Multi-criteria decision making approaches for supplier evaluation and selection: A literature review. European Journal of Operational Research, 202(1), 16-24.

Raguragavan, J., Hailu, A. and Burton, M. (2010). Economic valuation of recreational fishing in Western Australia. Working Paper 1001, School of Agricultural and Resource Economics, University of Western Australia, Crawley, Australia. Available online at: AgEcon Search (http://ageconsearch.umn.edu/handle/97473).

Saaty, T. L. and Vargas, L. G. (2000). Models, methods, concepts and applications of the analytic hierarchy process, Norwell, Kluwer Academic Publishers. 